\title{
A STROMAL CELL-DERIVED FACTOR-1 RELEASING MATRIX ENHANCES THE PROGENITOR CELL RESPONSE AND BLOOD VESSEL GROWTH IN ISCHAEMIC SKELETAL MUSCLE
}

\author{
D. Kuraitis ${ }^{1,2,3}$, P. Zhang ${ }^{1}$, Y. Zhang ${ }^{1,2}$, D.T. Padavan ${ }^{1}$, K. McEwan ${ }^{1,4}$, T. Sofrenovic ${ }^{1,2}$, D. McKee ${ }^{1}$, J. Zhang ${ }^{5}$, \\ M. Griffith ${ }^{2,6}$, X. $\mathrm{Cao}^{4}$, A .Musarò ${ }^{3}$, M. Ruel ${ }^{1,2}$ and E.J. Suuronen ${ }^{1,2, *}$ \\ ${ }^{1}$ Division of Cardiac Surgery, University of Ottawa Heart Institute, Ottawa, Canada \\ ${ }^{2}$ Department of Cellular and Molecular Medicine, University of Ottawa, Ottawa, Canada \\ ${ }^{3}$ DAHFMO-Unit of Histology and Medical Embryology, IIM, University of Rome La Sapienza, Rome, Italy \\ ${ }^{4}$ Faculty of Engineering, University of Ottawa, Ottawa, Canada \\ ${ }^{5}$ Department of Chemical and Biochemical Engineering, University of Western Ontario, London (Ont.), Canada \\ ${ }^{6}$ Integrative Regenerative Medicine Centre, Cell Biology Building, Linköping University, Linköping, Sweden
}

\begin{abstract}
Although many regenerative cell therapies are being developed to replace or regenerate ischaemic muscle, the lack of vasculature and poor persistence of the therapeutic cells represent major limiting factors to successful tissue restoration. In response to ischaemia, stromal cellderived factor-1 (SDF-1) is up-regulated by the affected tissue to stimulate stem cell-mediated regenerative responses. Therefore, we encapsulated SDF-1 into alginate microspheres and further incorporated these into an injectable collagen-based matrix in order to improve local delivery. Microsphere-matrix impregnation reduced the time for matrix thermogelation, and also increased the viscosity reached. This double-incorporation prolonged the release of SDF-1, which maintained adhesive and migratory bioactivity, attributed to chemotaxis in response to SDF-1. In vivo, treatment of ischaemic hindlimb muscle with microsphere-matrix led to increased mobilisation of bone marrow-derived progenitor cells, and also improved recruitment of angiogenic cells expressing the SDF-1 receptor (CXCR4) from bone marrow and local tissues. Both matrix and SDF-1-releasing matrix were successful at restoring perfusion, but SDF-1 treatment appeared to play an earlier role, as evidenced by arterioles that are phenotypically older and by increased angiogenic cytokine production, stimulating the generation of a qualitative microenvironment for a rapid and therefore more efficient regeneration. These results support the release of implanted SDF-1 as a promising method for enhancing progenitor cell responses and restoring perfusion to ischaemic tissues via neovascularisation.
\end{abstract}

Keywords: Cytokines, hydrogels, injectables, neovascularisation, regenerative medicine, vascular biology

*Address for correspondence:

E.J. Suuronen

Division of Cardiac Surgery, University of Ottawa Heart Institute,

40 Ruskin Street, Ottawa K1Y4W7, Canada

Telephone Number: 1-613-798-5555 x19087

FAX Number: 1-613-671-5367;

E-mail address: esuuronen@ottawaheart.ca
Myopathies, such as ischaemic heart disease and peripheral arterial disease (PAD) are significant killers in developed nations. In particular, PAD afflicts an estimated 27 million people in Europe and North America (Belch et al., 2003). This disease manifests when the flow of blood to extremities is acutely or chronically reduced (Selvin and Erlinger, 2004; Shamoun et al., 2008). Attributed to the lack of blood flow, symptoms typically include: pain, cramping, weakness and a poor ability to heal. To restore perfusion, current treatments include stent or vascular transplants with surgical intervention, or amputation; however, these options are invasive, carry risks, and amputation significantly reduces quality of life. Therefore, non-invasive options for restoring perfusion would be invaluable for PAD patients. Recent years have seen the generation of many novel approaches for developing tissue substitutes to replace or regenerate ischaemic muscle; however, the supply of sufficient and appropriate vasculature represents a major limiting parameter for a successful therapeutic approach (Ko et al., 2007; Kaully et al., 2009).

To augment reparative processes, regenerative therapies using bone marrow-, blood-, or tissue-derived progenitor cells have emerged; however, the results of these treatments are controversial and there is growing evidence to suggest that non-embryonic transplanted cells do not successfully integrate with host tissue (Murry et al., 2006; Suuronen et al., 2007). It is now believed that functional improvement results from neovascularisation and the restoration of blood flow to ischaemic muscle, and that this phenomenon is initiated, maintained, and enhanced by paracrine factors and secondary recruitment of progenitor cells (Cho et al., 2007; Formigli et al., 2007).

After ischaemic injury, an endogenous response to recruit the endogenous progenitor cells is initiated (Hofmann et al., 2005). Regarded as critical to this process is the up-regulation and release of the cytokine stromal cell-derived factor-1 (SDF-1) from ischaemic muscle (Askari et al., 2003) and the subsequent recruitment of circulating progenitor cells (CPCs), mobilised from distal tissues, such as bone marrow, into ischaemic tissue (De Falco et al., 2004). However, the stem cell recruitment response is short-lived and tissue accumulation is low (Wojakowski et al., 2004; Fazel et al., 2006). Recruited CPCs are observed to be pro-angiogenic (Park et al., 
2004; Suuronen et al., 2009) and are thought to augment functional recovery by promoting neovascularisation.

This study aims to use the SDF-1 signalling mechanism in an effort to amplify the endogenous response to ischaemia and the recruitment of vasculogenic progenitor cells. Herein, we report on the encapsulation of SDF-1 into microspheres, which are added to an injectable collagenbased matrix that thermogels at physiological temperature. We provide evidence that treatment with an SDF-1 releasing collagen matrix improves the vasculogenic response of ischaemic muscle, mediated by the recruitment of progenitor cells.

\section{Methods}

All reagents were obtained from Sigma-Aldrich (Oakville, Canada), unless otherwise indicated.

\section{Generation of microspheres}

Through a physical cross-linking reaction, blank (no peptide added) alginate microspheres were created with $1.25 \%$ sodium alginate $(\mathrm{w} / \mathrm{v})$. The solution was added to a syringe and forced through a J1 Encapsulation Device (Nisco, Zürich, Switzerland) at $1 \mathrm{~mL} / \mathrm{min}$, using a syringe pump, and $9.8 \mathrm{~L} / \mathrm{min}_{2}$ gas. Microspheres were allowed to fall into a $2 \% \mathrm{CaCl}_{2}(\mathrm{w} / \mathrm{v})$ cross-linking bath, and kept stirring for $20 \mathrm{~min}$ before washing with phosphate-buffered saline (PBS), and snap-freezing in liquid nitrogen. SDF1 loaded microspheres were created by adding $200 \mathrm{ng}$ SDF-1 per $g$ of alginate solution during sodium alginate solubilisation. Microspheres with both human (Cedarlane Laboratories, Hornby, Canada) and murine SDF-1 (Biovision, San Francisco, CA, USA) were generated, and stored at $-80^{\circ} \mathrm{C}$.

\section{Microsphere morphology}

Microspheres were thawed and suspended in PBS. Images were taken using an inverted phase contrast microscope (Olympus 1x81F), and microsphere size was assessed using Image-Pro Plus. Microsphere ultrastructure was observed using a Philips/FEI XL-30 scanning electron microscope (Hillsboro, OR, USA); WD = $7.0 \mathrm{~mm}$ and $\mathrm{keV}=1.2$. Microspheres were fixed in $3 \%$ glutaraldehyde for $2 \mathrm{~h}$, washed and subsequently dehydrated in various ethanol dilutions $(30 \%, 50 \%, 70 \%, 80 \%, 90 \%, 95 \%$, $99 \%$ ) for $5 \mathrm{~min}$ each before being critically point-dried. Specimens were mounted on stubs and coated with $\mathrm{Pd} / \mathrm{Au}$ using a Hummer Sputter Coater (Ladd Research, Williston, VT, USA).

\section{Matrix preparation}

As described previously (Suuronen et al., 2009), a collagen matrix was created on ice, using a crosslinking mixture containing a 1:1 molar ratio of $\mathrm{N}$-(3-dimethylaminopropyl)-N'-ethylcarbodiimide hydrochloride and N-hydroxysuccinimide (EDC/NHS; $13 \mathrm{mM}$ ) in 2(-N-morpholino) ethanesulfonic acid (MES) buffer, a solution of $1 \%$ porcine type I atelocollagen (w/v; Nippon Ham, Tskuba, Japan) and $40 \%$ chondroitin
sulphate-C (CSC) (w/v; Wako Chemicals, Osaka, Japan). The cross-linked collagen solution was diluted with PBS before adjusting the $\mathrm{pH}$ to $7.2 \pm 0.2$ using $1 \mathrm{~N} \mathrm{NaOH}$ or $\mathrm{HCl}$. The final concentration of collagen and CSC were $0.59 \%(\mathrm{w} / \mathrm{v})$ and $2.4 \%(\mathrm{w} / \mathrm{v})$, respectively. The proportion of microspheres in the matrix was $21 \%(\mathrm{w} / \mathrm{v})$, and when included, the SDF-1 concentration was $40 \mathrm{ng}$ / $\mathrm{mL}$. SDF-1 microsphere-matrix was prepared using the same procedure, except $400 \mathrm{mg}$ of microspheres was added in the PBS dilution step. For in vitro use, matrices were thermogelled for $20 \mathrm{~min}$ at $37^{\circ} \mathrm{C}$.

\section{Reagent sterilisation}

All liquid reagents (PBS, MES, CSC, alginate) were sterile filtered $(0.45 \mu \mathrm{m})$. Collagen ( $1 \%)$ was prepared with sterile water and the resulting solution was sterilised by exposure to ultraviolet (UV) light for a period of $15 \mathrm{~min}$.

\section{Rheology}

The rheological properties of the collagen matrix were measured using a Brookfield R/S Plus Rheometer as previously described (Deng et al., 2010). Samples of collagen matrix or microsphere-collagen matrix $(1.5 \mathrm{~mL})$ were subjected to a constant shear rate of $5 \mathrm{~s}^{-1}$ for 20-30 min using a C50-2 spindle (spindle gap of $4 \mu \mathrm{m}$, according to the spindle specifications), and the temperature was maintained at $37^{\circ} \mathrm{C}$. Rheo3000 v1.2 software was used to monitor viscosity $(\mathrm{Pa} \cdot \mathrm{s})$ and time to gelation (s). The time at which maximum viscosity was reached was considered to be the material's time to gelation. In addition to time viscosity profiles, elastic storage $\left(G^{\prime}\right)$ and loss $\left(G^{\prime \prime}\right)$ modulus as a function of temperature at a frequency of 1 $\mathrm{Hz}$ was also measured.

\section{SDF-1 release}

Microspheres containing human SDF-1 were used to assess release kinetics. Microspheres alone or embedded in a collagen matrix were added to a $20 \mathrm{~mL}$ flask with 5 $\mathrm{mL}$ of PBS. At various time points, samples were taken and immediately frozen at $-80^{\circ} \mathrm{C}$ and fresh PBS was added to replace the removed aliquot volume. SDF-1 content in the supernatant was assessed using an ELISA kit (R\&D Systems, Minneapolis, MN, USA), according to the manufacturer's protocol. Data is reported as a ratio of concentration at time $t$, relative to the maximal release.

\section{Release kinetics}

To analyse SDF-1 release from microspheres (+/- matrix embedding), various release kinetic models were used to describe the observed release kinetics. Correlation coefficients were determined for data fit to zero-order release (Hadjiioannou et al., 1993), first-order release (Bourne et al., 2002), Higuchi (Higuchi, 1963), HixsonCrowell (Hixson and Crowell, 1931) and KorsmeyerPeppas (Korsmeyer et al., 1983) models.

\section{Cell culture}

Procedures for the isolation of human circulating progenitor cells (CPCs) were approved by the Human Research Ethics Board of the University of Ottawa Heart Institute. 
After obtaining informed consent, total peripheral blood mononuclear cells (PBMCs) were isolated from the blood of healthy human volunteers by Histopaque 1077 densitygradient centrifugation, as previously described (Ruel et al., 2005). Cells were cultured on fibronectin-coated plates in endothelial basal medium (EBM-2; Clonetics, Guelph, Canada) containing $5 \%$ FBS (v/v), VEGF, R ${ }^{3}$-IGF-1, and hEGF supplements. After $4 \mathrm{~d}$ in culture, supernatant and non-adherent cells were removed, and adherent populations were considered to be circulating progenitor cells (CPCs).

\section{Adhesion assay}

CPCs $\left(2 \times 10^{4}\right)$ were resuspended in $1 \mathrm{~mL}$ of medium and seeded in 12-well dishes with fibronectin-coated coverslips, containing medium with $50 \mathrm{mg}$ of blank microspheres or medium with $50 \mathrm{mg}$ of human SDF-1 loaded microspheres. After $1 \mathrm{~h}$ at $37{ }^{\circ} \mathrm{C}$, medium was aspirated and adherent cells were fixed with $4 \%$ paraformaldehyde (PFA). Coverslips were washed with PBS and mounted on slides with 4',6-diamidino-2-phenylindol-(DAPI)-containing mounting medium (Vector Laboratories, Burlington, Canada). Six random fields-of-view were imaged using a Zeiss Z1 fluorescent microscope and $\mathrm{DAPI}^{+}$cells were counted.

\section{Migration assay}

CPCs $\left(2 \times 10^{4}\right)$ in VEGF-free medium were added to the top chamber of a Transwell tissue culture well (Corning, New York, NY, USA). The lower chamber contained VEGF-free medium with $50 \mathrm{mg}$ of blank microspheres or VEGF-free medium with $50 \mathrm{mg}$ of human SDF-1 loaded microspheres. The bottom of each well contained a fibronectin-coated coverslip. After $24 \mathrm{~h}$ of incubation, cells were fixed, DAPIstained, visualised, and counted.

\section{Chemokinesis versus chemotaxis assay}

To investigate the mode of action through which SDF-1 induces CPC migration, assays, based on a previously described protocol for the evaluation of chemokinesis versus chemotaxis (Misiak-Tloczek and BrzezinskaBlaszczyk, 2009), were carried out. Three treatment conditions (represented as the presence of SDF-1 in the upper well/lower well) were tested: SDF-1/0 (SDF-1 only in the upper well); SDF-1/SDF-1 (SDF-1 in both upper and lower wells); 0/SDF-1 (SDF-1 in the lower well only). SDF-1 was used at a concentration of $9 \mathrm{ng} / \mathrm{mL}$, as this is the approximate amount released from microspheres after $24 \mathrm{~h}$. Quantification was performed in the same manner as described for the migration assay above.

\section{Animal model}

All procedures were performed with the approval of the University of Ottawa Animal Care Committee, in compliance with the National Institute of Health's Guide for the Care and Use of Laboratory Animals. Bone marrow transplantation was performed as previously described (Whitman et al., 2004). Briefly, female C57BL/6J mice (8-9 weeks old, Jackson Laboratories, Bar Harbor, ME, USA) were irradiated with a total of 900 rads from a caesium source, delivered in 2 equal doses, $3 \mathrm{~h}$ apart. Donor bone marrow cells $\left(7 \times 10^{6}\right)$ from green fluorescent protein (GFP) transgenic mice (C57BL/6-Tg(CAG-EGFP)10sb/J, Jackson Laboratories) were injected into the tail vein of irradiated recipient mice. Six weeks after transplantation, proximal femoral arteries in left hindlimbs were ligated as described (Limbourg et al., 2009), using 4.0 silk thread, under $2 \%$ isoflurane. Limbs subsequently received $80 \mu \mathrm{L}$ injection of: 1) PBS $(n=9)$; 2) collagen matrix $(n=8)$; or 3 ) collagen matrix containing murine SDF-1 microspheres $(n=8)$. Treatments were delivered by 3 equivolumetric injections into the adductor muscle downstream of the ligation site, using a 27-gauge needle.

Blood perfusion of both hindlimbs was measured before and after ligation, and at days 4,7 and 14 postoperatively using a multifibre needle probe $(8$ separate collecting fibres), and a laser Doppler blood flow monitor (Moor Instruments, Axminster, UK).

Blood samples $(\sim 100 \mu \mathrm{L})$ were procured from the right saphenous veins on days 0 (pre-operative baseline), 1, 4, 7 and 14 post-operatively. PBMCs were isolated using density-gradient centrifugation and immediately characterised using flow cytometry as described below.

\section{Flow cytometry}

Cells were labelled with antibodies against the following antigens: c-kit (Southern Biotech, Birmingham, AL, USA), CXCR4 (BD Biosciences, Mississauga, Canada), and flk-1 (eBioscience, San Diego, CA, USA), and analysed with a FACSAria flow cytometer (BD Biosciences). Isotypematched immunoglobulin antibodies were used as controls.

\section{Immunohistochemistry}

Animals were sacrificed at day 14. Hindlimb muscle tissue was collected and fixed overnight in PFA before paraffinisation. All samples were analysed in crosssection. Samples were de-paraffinised and hydrated with sequential washes in toluene and decreasing concentrations of ethanol. Antigen retrieval was performed using boiling citrate buffer. All staining was performed in PBS containing $10 \%$ normal horse serum (Vector Laboratories). The following antibodies were used: anti- $\alpha$-smooth muscle actin (SMA; pre-diluted, Abcam, Cambridge, MA, USA), anti-GFP (1:100; Abcam), and anti-CXCR4 (1:50; Abcam). For all tissue sections, mounting medium with DAPI (Vector Laboratories) was used to visualise nuclei. All measurements and cell counts were determined from 6 random microscopic fields-of-view and averaged from 2 blinded observers.

\section{Cytokine Antibody Arrays}

Relative cytokine levels in hindlimb lysates and serum from sacrificed animals ( $n=5$ per treatment group) were analysed using RayBio Mouse Cytokine Antibody Array Kits (Raybiotech, Norcross, GA, USA), according to the manufacturer's protocol.

\section{Statistical Analysis}

Unless otherwise stated, values are expressed as means \pm standard error. Statistical analyses were performed using SPSS (IBM, Somers, NY, USA). Comparisons of 

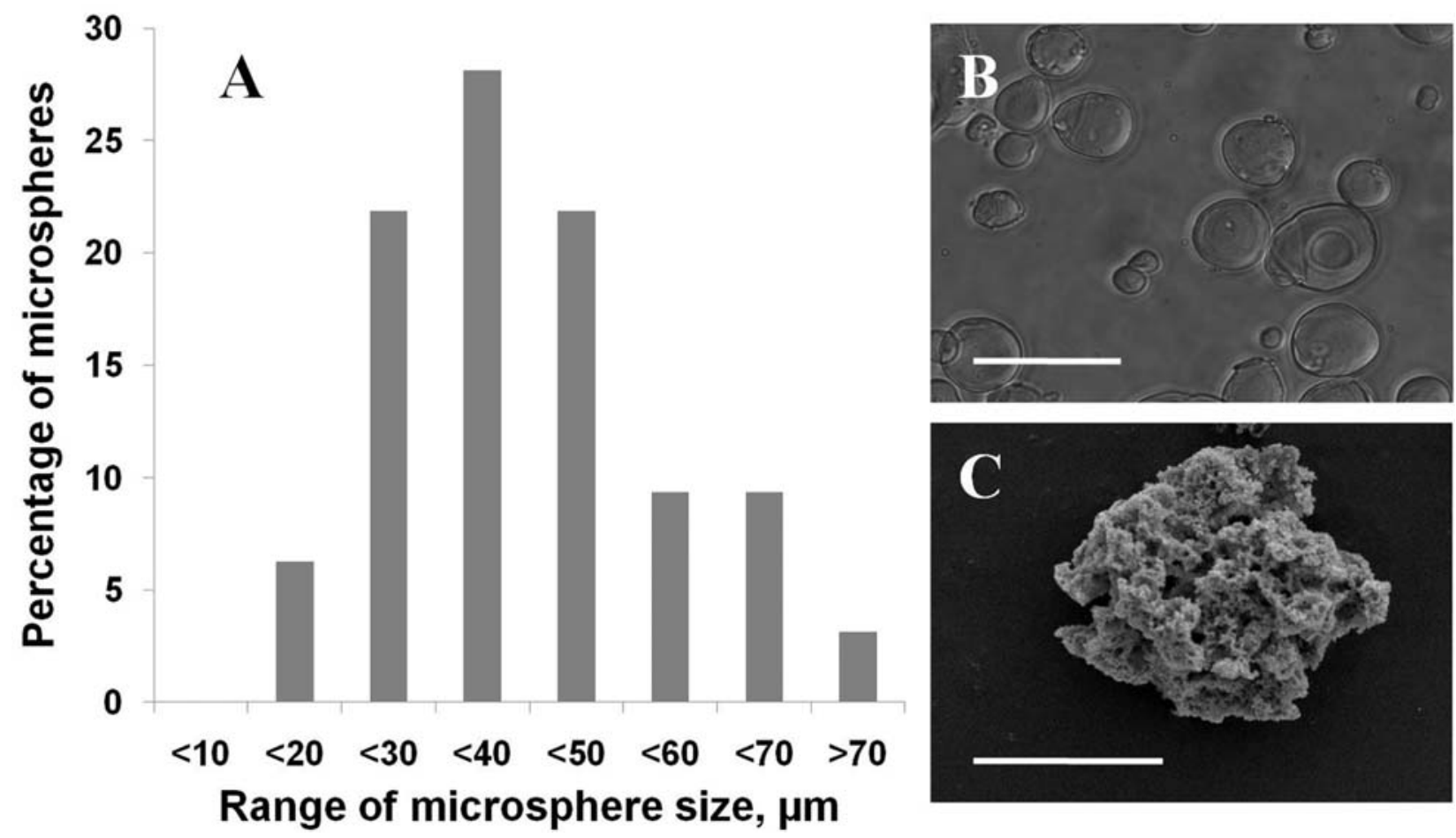

Fig. 1. Characterisation of SDF-1-containing alginate microspheres. Average size of microspheres was $38.5 \mu \mathrm{m}$ (A). Microspheres displayed a rounded morphology in saline solution $(\mathbf{B} ; 400 \mathrm{x})$, and a lattice structure after drying and imaging using scanning electron microscopy $(\mathbf{C} ; 379 \mathrm{x})$. Scale bars $=50 \mu \mathrm{m}$.

continuous data between groups were performed with a one-way analysis of variance and comparisons between individual groups were performed with a two-tailed Student's t-test. For in vitro CPC analysis, results were paired by donor, and subjected to a paired $t$-test. Probability values of $p<0.05$ were considered statistically significant.

\section{Results}

\section{Generation of SDF-1 microspheres}

Microspheres had a mean diameter of $38.5 \mu \mathrm{m}( \pm 14.0$ $\mu \mathrm{m}$ (SD); Fig. 1A). When hydrated, microspheres had a smooth, spherical morphology (Fig. 1B), and a rougher surface upon dehydration as visualised by scanning electron microscopy (SEM) (Fig. 1C).

\section{Microsphere-matrix impregnation}

The addition of microspheres to the collagen matrix reduced the time to gelation and caused the matrix to solidify at a greater viscosity, as early as $400 \mathrm{~s}$ after application ( $p=0.05$; Fig. 2A, 2B), which was maintained over time. Maximum viscosity reached was greater for the matrix containing microspheres $(1.42 \mathrm{~Pa} \cdot \mathrm{s})$, compared to matrix alone $(1.18 \mathrm{~Pa} \cdot \mathrm{s} ; p=0.003)$. Microspheres in solution released their SDF-1 content within $1 \mathrm{~d}$, but matrix impregnation prolonged the maximal release up to approximately $10 \mathrm{~d}$ (Fig. 2C). Analysis of SDF-1 release kinetics shows that release from microspheres best fits a first order model, indicated by the greatest correlation coefficient, but after impregnation in a matrix, release follows the Higuchi model (Table 1, Fig. 2D).

\section{Bioactivity of SDF-1 microspheres}

Blank microspheres did not confer any difference in adhesion potential with cultured CPCs, but the addition of SDF-1 loaded microspheres supported an increase in adhesive CPCs by 2.3-fold after $1 \mathrm{~h}$ of exposure ( $p=0.04$; Fig. 3A-C). When CPCs were given a chemotactic stimulus of blank or SDF-1 loaded microspheres, 3.2-fold more cells migrated towards the SDF-1-releasing microspheres than the blank ones after $24 \mathrm{~h}$ ( $p=0.004$; Fig. 3D-F).

Table 1. Correlation coefficients (R2) for SDF-1 release from microspheres alone or embedded in a collagen matrix, based on classical drug release models.

\begin{tabular}{|c|c|c|c|c|c|}
\hline & $\begin{array}{c}\text { Zero } \\
\text { Order }\end{array}$ & $\begin{array}{c}\text { First } \\
\text { Order }\end{array}$ & $\begin{array}{c}\text { Hixson- } \\
\text { Crowell }\end{array}$ & Higuchi & $\begin{array}{c}\text { Korsmeyer- } \\
\text { Peppas }\end{array}$ \\
\hline Free MS & 0.93 & 0.95 & 0.94 & 0.84 & 0.92 \\
\hline $\begin{array}{c}\text { Matrix- } \\
\text { Embedded MS }\end{array}$ & 0.66 & 0.75 & 0.78 & 0.94 & 0.59 \\
\hline
\end{tabular}



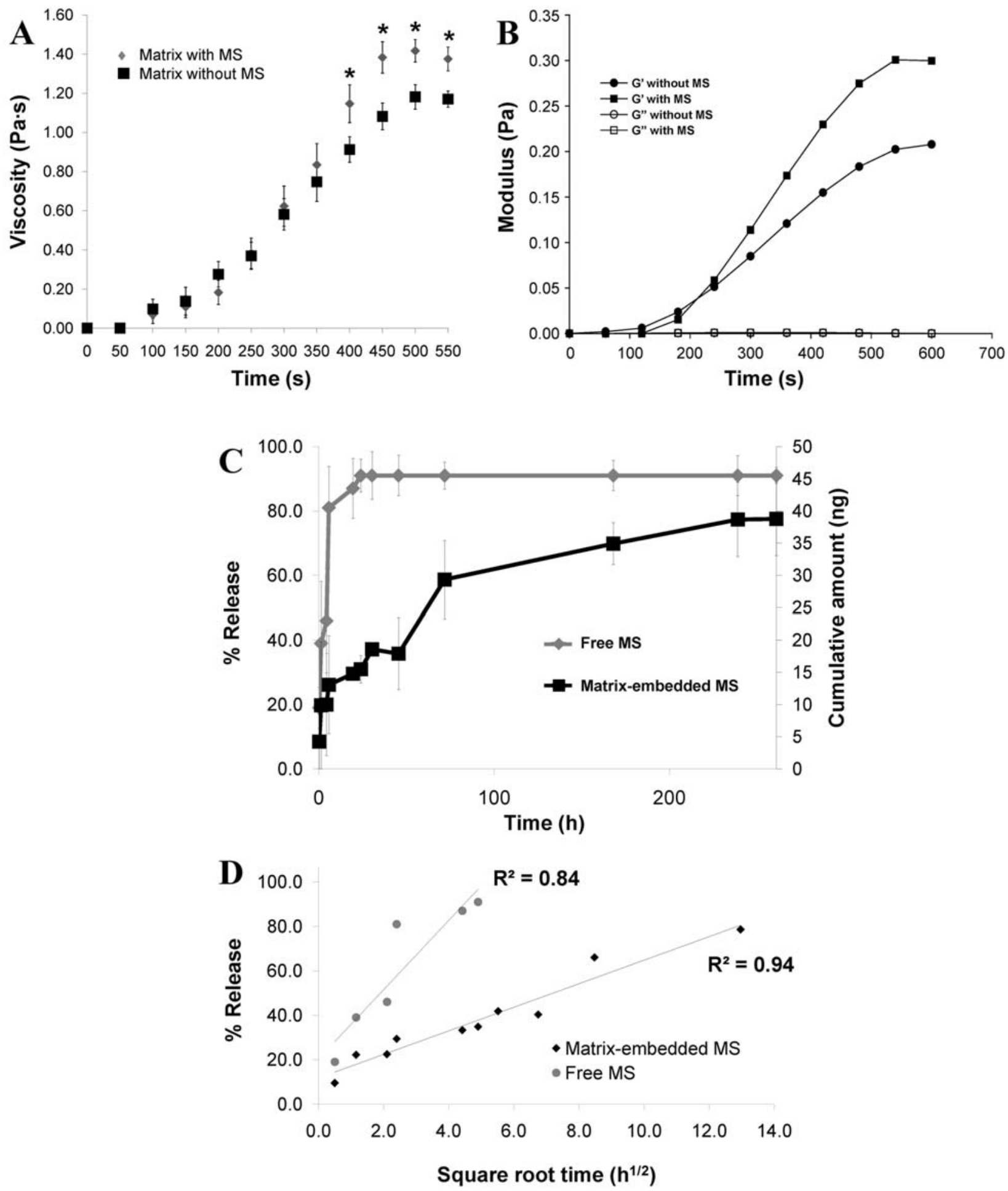

Fig. 2. Matrix-microsphere effects. After microsphere (MS) impregnation into collagen matrix, rheological properties of the matrix were altered: time to gelation was reduced by $16 \%$, and viscosity increased by $22 \%(\mathbf{A} ; n=10)$. Differences in gelation were first noted at $400 \mathrm{~s}$. B shows representative modulus versus time curves, which illustrate G' (storage) and G' (loss) values for the different hydrogels. The burst-release effect of SDF-1 was reduced upon incorporation into matrix; the maximal release was delayed from approximately 1 to $10 \mathrm{~d}(\mathbf{C} ; n=3)$. Analysis of release kinetics demonstrates that when microspheres are embedded in a matrix, SDF-1 release fits the Higuchi model $\left(\mathbf{D} ; \mathrm{R}^{2}=0.94\right) .{ }^{*} p<0.05$ versus matrix without microspheres at the same time point. 

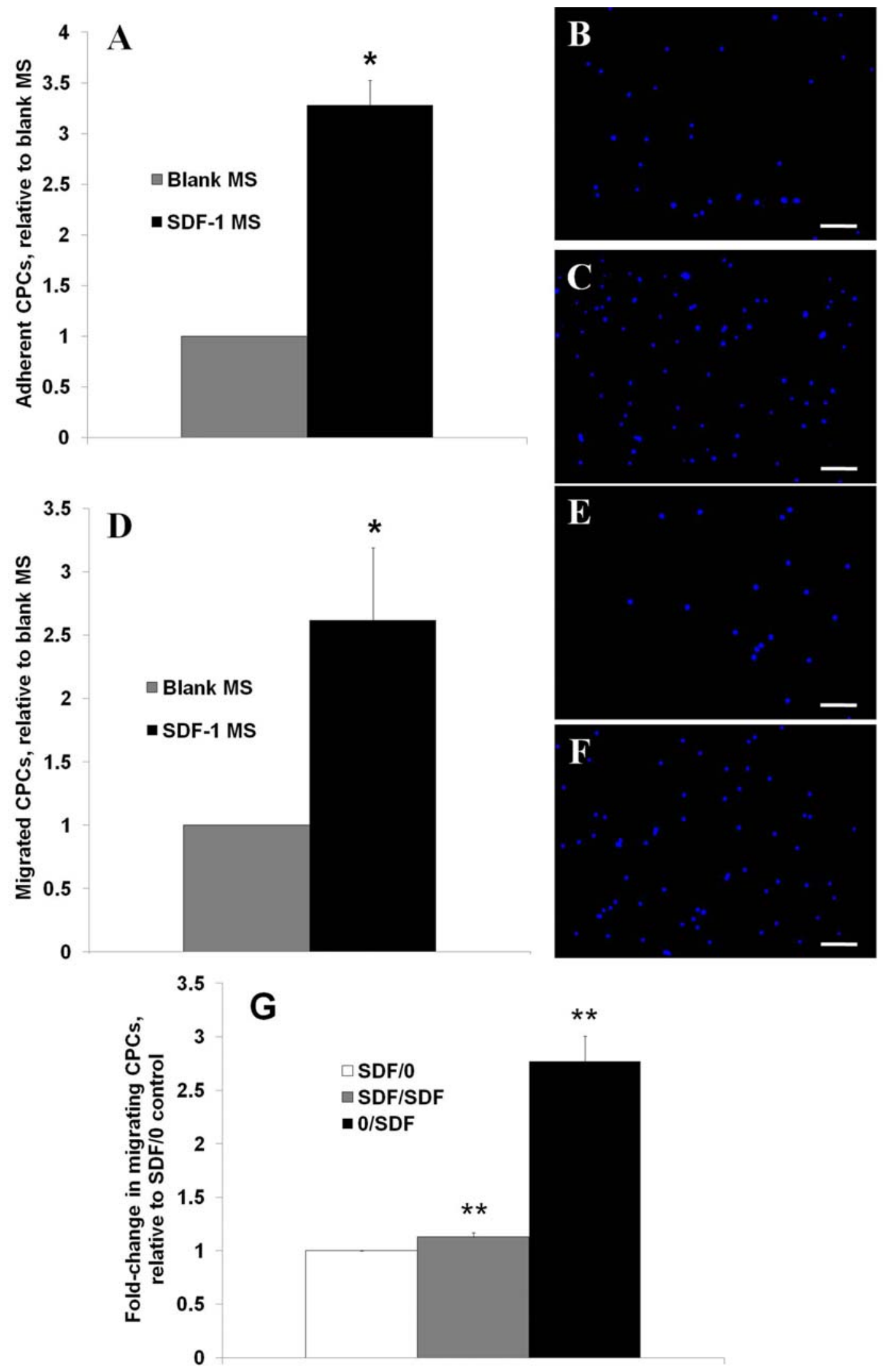

Fig. 3. Effects of blank (no SDF-1) and SDF-1 loaded microspheres on cultured primary CPCs. In the presence of SDF-1 loaded microspheres (MS), over 2-fold more CPCs were adherent to fibronectin within 1 hour of exposure $(\mathbf{A} ; n=4) ; \mathbf{B}, \mathbf{C}$ are representative images of adherent CPCs in the presence of blank or SDF-1 loaded microspheres, respectively. More CPCs migrated towards SDF-1 microspheres $(\mathbf{D} ; n=4) ; \mathbf{E}, \mathbf{F}$ are representative images of blank and SDF-1 loaded microsphere-induced migration of CPCs, respectively. The effect of SDF-1 on CPC migration was mainly chemotactic, rather than chemokinetic, as evidenced by the greater migratory effect of CPCs towards SDF-1 when it is presented as a gradient (G). Scale bars $=100 \mu \mathrm{m} .{ }^{*} p<0.05 ; * * p<0.05$ vs. all others. 

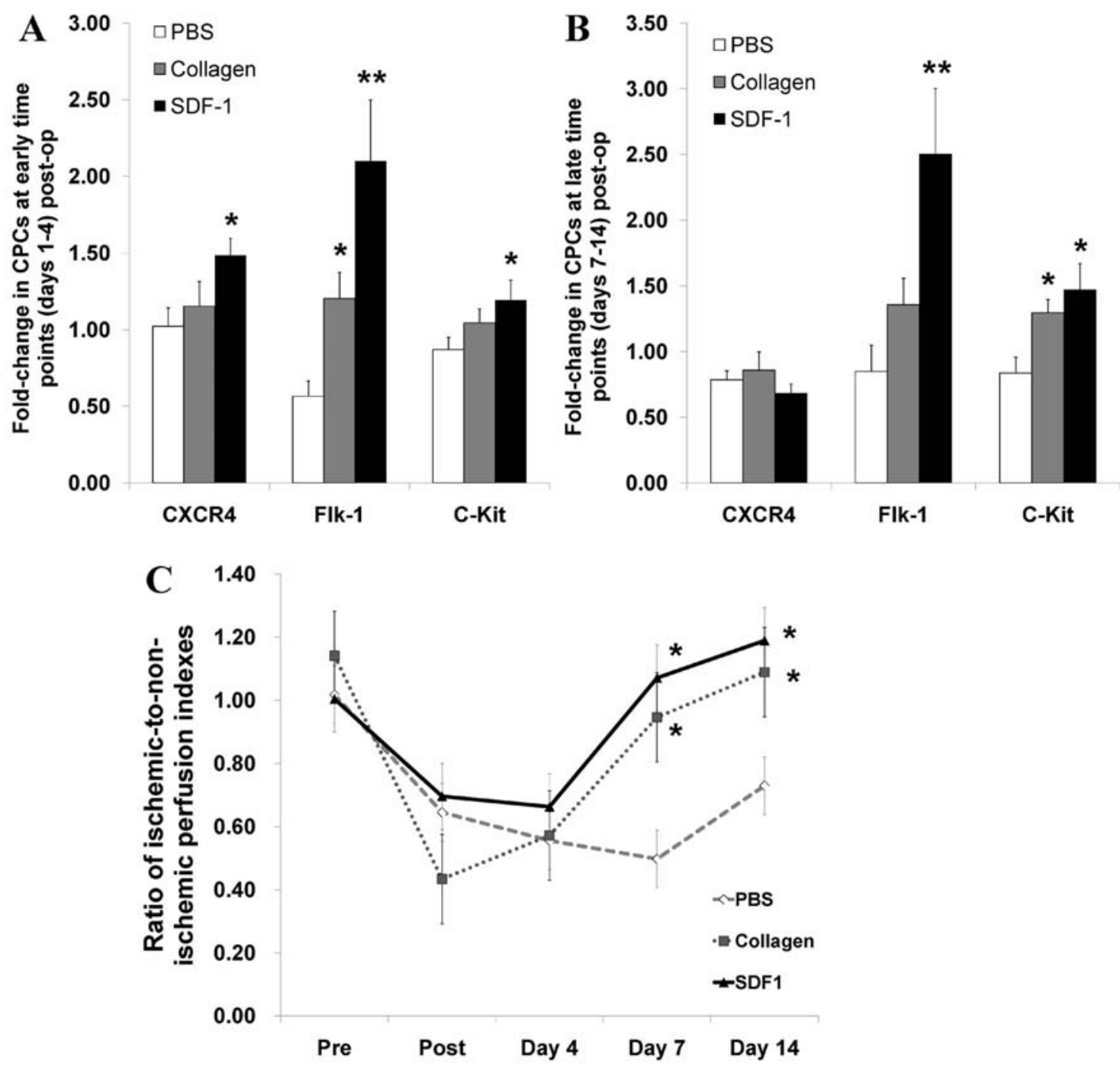

Fig. 4. Functional effects of collagen \& SDF-1 microsphere matrix treatments in vivo. At early time points after treatment (A; days 1-4), animals receiving SDF-1 microsphere-matrix (SDF-1) had greater numbers of circulating CPCs. This was also observed at later time points (B; days 7-14). By 7 d post-op, hindlimb perfusion was restored to baseline levels with matrix treatments (C; $n=8-9$ per group). ${ }^{*} p<0.05$ versus PBS; $* * p<0.05$ versus PBS \& collagen.

\section{SDF-1 mediated-migration of CPCs is mainly chemotactic}

Compared to the lack of a chemotactic stimulus (absence of SDF-1 in the lower well), chemokinesis, stimulated by equivalent amounts of SDF-1 in the upper and lower chambers, increased CPC movement to the lower chamber by $13 \%(p=0.04$; Fig. $3 \mathrm{G})$. The chemotactic stimulus with SDF-1 only in the lower chamber induced the greatest migration of CPCs, by $177 \%(p=0.006$; Fig. $3 \mathrm{G})$.

\section{In vivo mobilisation of CPCs by SDF-1 treatment}

Based on the in vitro chemotactic properties of SDF1 microsphere matrix, we defined whether the construct is able to enhance the recruitment of CPC in an in vivo system. $\mathrm{GFP}^{+}$(bone marrow-derived) CPCs in the peripheral blood were analysed over time, and compared to baseline. Interestingly, the SDF-1 microsphere matrix treatment significantly increased circulating $\mathrm{CXCR}^{+}$cells (by 45 $\% ; p=0.02$ ), flk- $1^{+}$cells (by $105 \% ; p=0.001$ ), and c-kit ${ }^{+}$ cells (by $18 \% ; p=0.04$ ) at early time point post injury (Fig. 4A) and was able to maintain elevated numbers of circulating flk- $1^{+}$cells (by $149 \% ; p=0.002$ ) and c-kit ${ }^{+}$ cells (by $48 \% ; p=0.01$ ) for an extended period (7-14 d) post operation (Fig. 4B). Notably, the collagen matrix alone increased circulating $\mathrm{flk}^{+}$cells (by $20 \% ; p=0.009$ ) at the earlier evaluation and c-kit ${ }^{+}$cells at both early (by $48 \%$; $p$ $=0.01$ ) and late time point (by $29 \% ; p=0.02$; Fig. 4A, B).

\section{Restoration of perfusion by matrix treatments}

Indeed, both matrix treatments (with or without SDF-1 microspheres) were able to restore perfusion to baseline levels by one week post-treatment, compared to PBS controls (Fig. 4C; $p<0.04$ ), which was maintained at two weeks post-treatment $(p<0.05)$.

\section{Arteriole density of ischaemic hindlimbs}

Arteriole density in ischaemic hindlimbs was not different between collagen and SDF-1 collagen matrices $(p=0.9)$; 

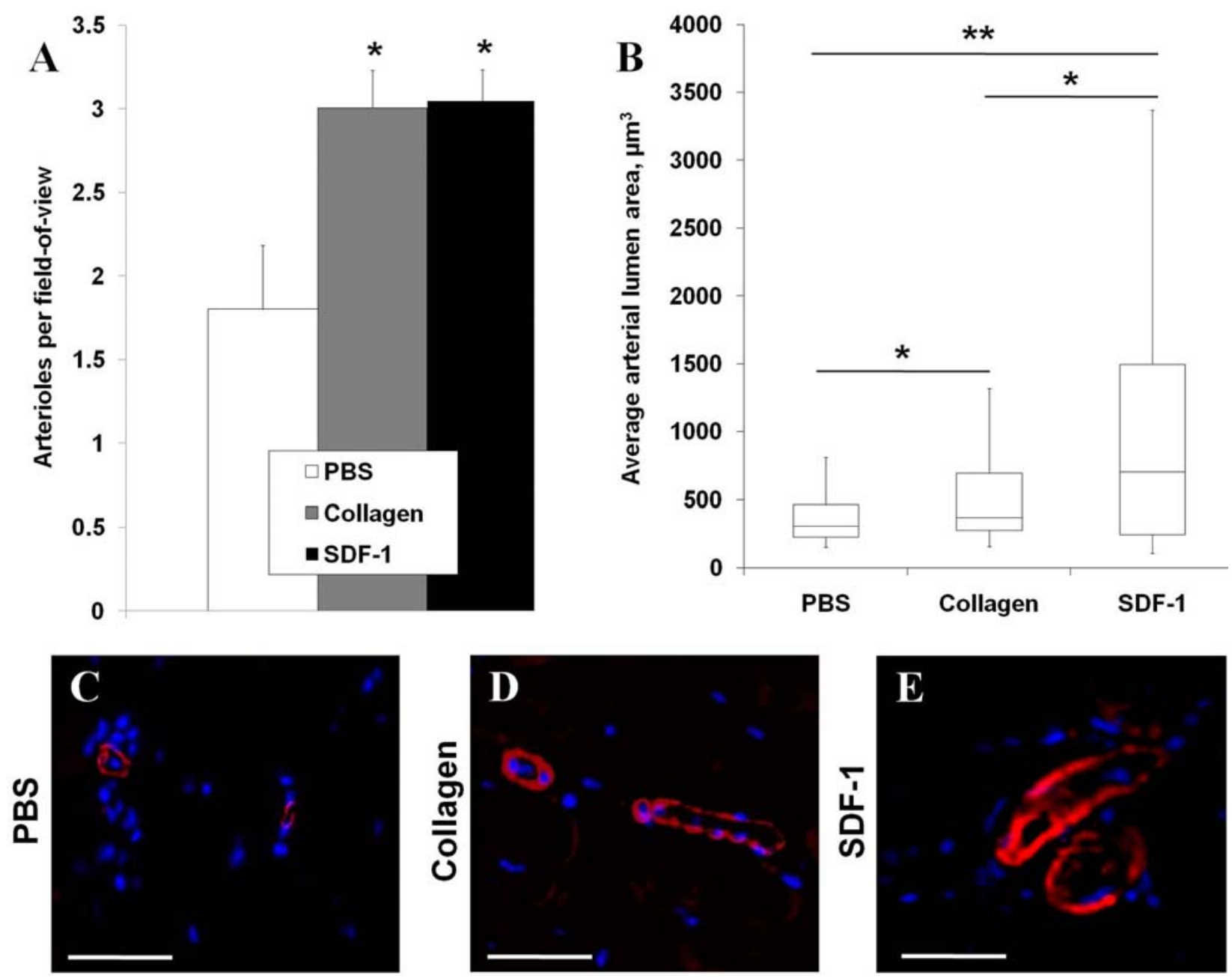

Fig. 5. Assessment of vasculature in treated hindlimbs. There was a trend for increased arteriole counts with matrix treatments (A). Larger arterioles were produced in animals receiving collagen or SDF-1 microsphere-matrix (SDF-1) treatments, with the SDF-1 microsphere-matrix treatment leading to the largest arterioles (B). C, D, E are representative images of arterioles (indicated by $\mathrm{SMA}^{+}$, red), and counter stained with DAPI (blue). Scale bars $=50 \mu \mathrm{m} . n=6-8$ per group. $* * p \leq 0.05 ; * 0.05<p<0.10$.

however, both matrix and SDF-1 microsphere matrix treatments increased arteriole density compared to PBS by $67 \%(p=0.01) \& 69 \%(p=0.02)$, respectively (Fig. $5 \mathrm{~A}-\mathrm{E})$. Mean arteriole size was greater in the SDF-1 microsphere matrix treatment group compared to PBStreated mice $(p<0.05$; Fig. 5B-E). There was also a trend for greater arteriole cross-sectional area with SDF-1 microsphere matrix treatment compared to collagen matrix $(p=0.09)$, and for collagen matrix treatment compared to PBS ( $p=0.08$; Fig. 5B).

\section{Recruitment of bone marrow-derived cells to treated hindlimbs}

SDF-1 microsphere matrix and collagen matrix treatments recruited 17.7- and 4.2-fold more $\mathrm{GFP}^{+}$cells to treated hindlimbs, compared to PBS ( $p=0.0007$ and 0.02), respectively (Fig. 6A-D). There was a trend for SDF-1 microsphere matrix treatment to recruit more $\mathrm{GFP}^{+}$cells than collagen matrix alone ( $p=0.06$; Fig. $6 \mathrm{~A})$.
Engraftment of CXCR4 ${ }^{+}$cells in ischaemic hindlimbs Overall, SDF-1 microsphere matrix treatment recruited 4.3- and 1.8-fold more CXCR4 ${ }^{+}$cells to treated hindlimbs compared to PBS and collagen $(p=0.0004$ and 0.05 ; Fig. 7A-D). Separating the analysis of $\mathrm{CXCR} 4^{+}$cells into those recruited from the marrow versus those recruited locally, SDF-1 microsphere matrix treatment recruited 4.9-fold more $\mathrm{CXCR}^{+} \mathrm{GFP}^{+}$(bone marrow-derived) and 4.5-fold more CXCR4 ${ }^{+} \mathrm{GFP}^{-}$(local) cells, compared to PBS and collagen ( $p=0.008$ and 0.02 ; Fig. 7A). Collagen matrix alone also recruited 2.8 -fold more $\mathrm{CXCR}^{+} \mathrm{GFP}^{+}$cells compared to PBS ( $p=0.03$; Fig. 7A).

\section{Cytokine profiles}

In the hindlimb (Fig. 8A), interleukin-1 $\alpha(\mathrm{IL}-1 \alpha ; p=0.04)$ and monocyte inhibitory protein-3 $\alpha$ (MIP-3 $\alpha ; p=0.04$ ) were reduced, and vascular cell adhesion molecule-1 (VCAM-1; $p=0.03$ ) and insulin-like growth factor-1 $(\mathrm{IGF}-1 ; p=0.03)$ were increased with SDF-1 microsphere 

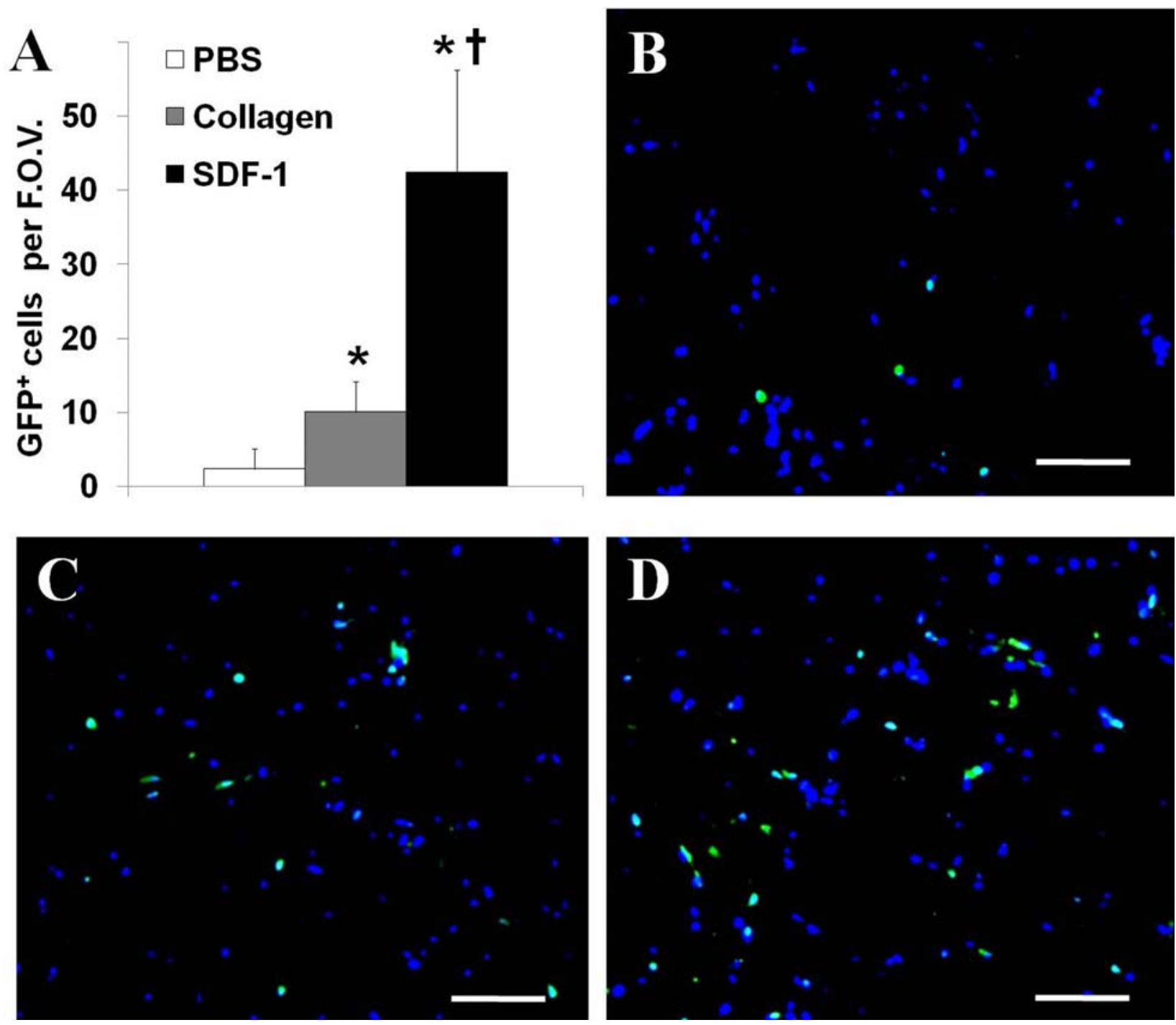

Fig. 6. Recruited bone marrow-derived cells. More $\mathrm{GFP}^{+}$cells were engrafted in ischaemic hindlimbs treated with collagen or SDF-1 microsphere-matrix (SDF-1), with a trend for more GFP ${ }^{+}$cells in the SDF-1 microsphere-matrix treatment, compared to matrix alone (A). Representative images of $\mathrm{GFP}^{+}$cells recruited to PBS- (B), collagen matrix-(C), or SDF-1 microsphere-matrix- (D) treated hindlimbs. Scale bars $=100 \mu \mathrm{m} ; n=6-8$ per group. ${ }^{*} p \leq$ 0.02 vs. PBS, ${ }^{\dagger} p=0.06$ vs. collagen.

matrix treatment. In the serum (Fig. 8B): L-selectin was increased with SDF-1 microsphere matrix treatment $(p=0.01)$ and reduced with collagen alone $(p=0.01)$; basic fibroblast growth factor (bFGF) was increased with collagen alone $(p<0.001)$ and with SDF-1 microsphere matrix treatment $(p=0.02)$; and VCAM-1 was reduced with SDF-1 microsphere matrix treatment compared to collagen matrix $(p=0.007)$ and PBS $(p<0.001)$. For both serum and hindlimb, no significant differences between any treatments were observed for the following inflammatory cytokines: GM-CSF, TNF- $\alpha$, IL- $1 \beta$ and IL-6 (all $p>0.4$ ).

\section{Discussion}

In this study, we demonstrated that the release of SDF-1 from alginate microspheres can be effectively prolonged by incorporation of the microspheres into a thermogelling collagen matrix. Released SDF-1 was bioactive, supported rapid adhesion and migration of CPCs, and also stimulated the mobilisation of CPCs from bone marrow when applied to ischaemic muscle. Both matrix alone and SDF-1-releasing matrix restored perfusion and improved arteriole density by 2 weeks, but the SDF- 1 treatment best supported the growth of arterioles. SDF-1 microsphere matrix treatment also recruited more bone marrow-derived cells and local CXCR4 ${ }^{+}$cells to the ischaemic muscle, and altered levels of local angiogenic factors.

Incorporation of alginate microspheres into the collagen matrix increased the hydrogel's viscosity and reduced the time to gelation. This is thought to be mediated by the cross-linking reaction, whereby functional groups on collagen $\left(-\mathrm{NH}_{2}\right)$ and alginate $(-\mathrm{COOH})$ are covalently bound by EDC/NHS (Mitra et al., 2011), increasing the total number of cross-links within the material and enhancing its strength, as has been previously reported (Liu et al., 2008). An earlier onset of gelation is advantageous 

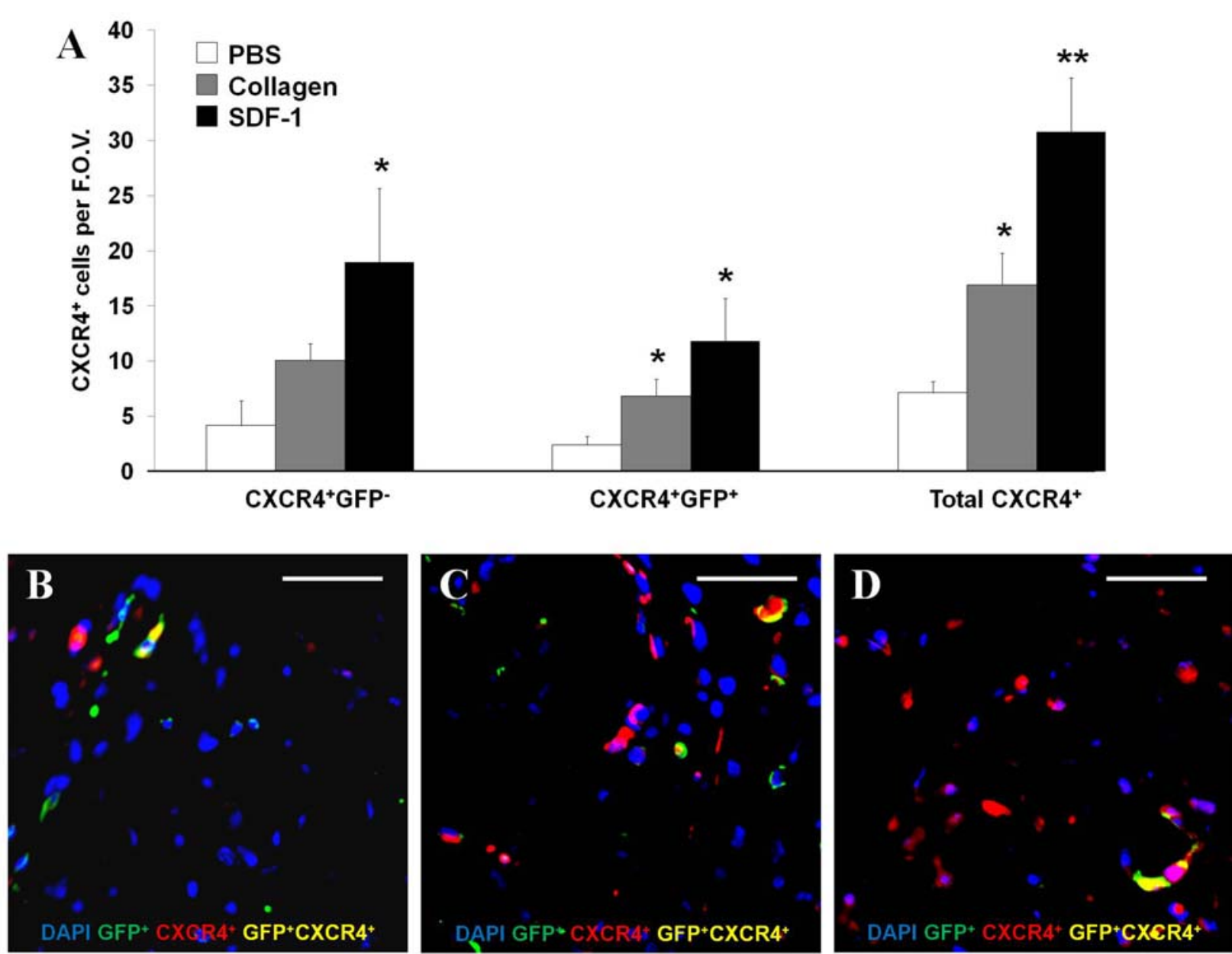

Fig. 7. Localised CXCR4 ${ }^{+}$cells. SDF-1 microsphere-matrix (SDF-1) treatment recruited more CXCR4 ${ }^{+}$cells, from both bone marrow $\left(\mathrm{GFP}^{+}\right)$and locally $\left(\mathrm{GFP}^{-}\right)$. (A) Representative images of $\mathrm{GFP}^{+}$(green), $\mathrm{CXCR}^{+}$(red), or $\mathrm{GFP}^{+} \mathrm{CXCR}^{+}$cells (yellow) in PBS- (B), collagen matrix- (C), or SDF-1 microsphere-matrix- (D) treated hindlimbs. Scale bars $=200 \mu \mathrm{m} ; n=6-8$ per group. ${ }^{*} p<0.05$ vs. PBS, ${ }^{*} p<0.05$ vs. all.

in a clinical setting, allowing for a reduction in the time required for stable material integration within host tissue. Additionally, a positive correlation between hydrogel viscosity and resistance to degradation has been noted (Yang et al., 2010), suggesting a better persistence in vivo of microsphere-containing hydrogels.

During the period of release, SDF-1 kinetics from matrix-embedded microspheres fit the Higuchi model of release whereby the initial drug concentration $>>$ drug solubility in the matrix, swelling is negligible, perfect sink conditions are maintained and edge effects are negligible, suggesting that diffusion is the primary mechanism of SDF-1 release (Higuchi, 1963). In contrast, microspheres alone initially demonstrated a burst release followed by a first order release of SDF-1. Although a burst-release effect was observed with microspheres alone, the embedding of microspheres in matrix was able to prolong the SDF-1 release by 10 -fold. This observation can be explained by the properties of the microspheres and the collagenhydrogel system. Hydrogels have an innate ability to retain small peptides (Cadee et al., 2002; Ruvinov et al., 2010), and incorporation of peptide-containing microspheres into hydrogels has been shown previously to extend the release profile of the peptide (Kempen et al., 2008). SDF-
1 bioactivity was maintained during the microsphere generation and cross-linking procedure; upon its release, SDF-1 augmented rapid adhesion of CPCs, as well as inducing chemotaxis of CPCs, rather than chemokinesis, indicating its ability to induce CPC homing towards a chemotactic gradient rather than the induction of random mobilisation.

In the ischaemic hindlimb study, marrow-mobilised cells expressing the SDF-1 receptor CXCR4 were increased in circulation of SDF-1 microsphere matrixtreated animals at early time points, but this effect was later lost. This can be explained by previous studies showing the eventual down-regulation of $\mathrm{CXCR} 4$ following cytokine-induced mobilisation from the bone marrow (Kim et al., 2006). More specifically, CXCR4 expression is dose-dependent on SDF-1 levels; doses of $\leq 1 \mu \mathrm{g}$ in a mouse model have shown CXCR4 levels equivalent to controls that did not receive SDF-1 (Kimura and Tabata, 2010). Interestingly, higher doses of SDF-1 have the same effect, suggesting a potential negative feedback loop for the SDF-1/CXCR4 axis. Notably, SDF-1 microsphere matrix treatment also stimulated an early mobilisation of flk- $1^{+}$ and c-kit ${ }^{+}$cells from the bone marrow into circulation, and maintained this effect up to 2 weeks post-treatment. 

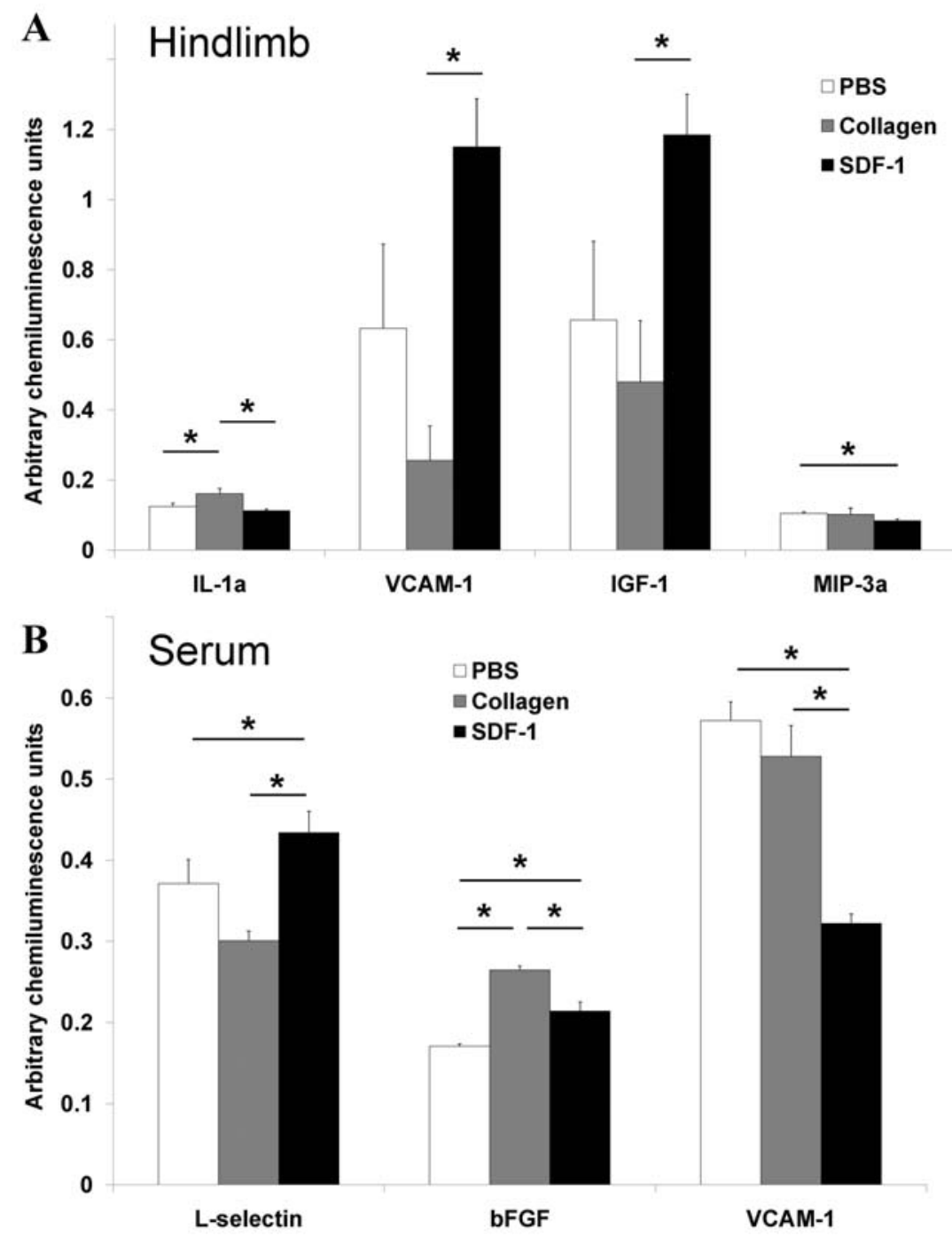

Fig. 8. Cytokine profiles. Observed differences in cytokines in hindlimb lysates (A) and serum (B), two weeks after treatment $(n=5)$. $* p<0.05$.

CXCR4 is SDF-1's exclusive receptor and CXCR4 ${ }^{+} \mathrm{CPCs}$ are reduced over time, mechanisms other than SDF-1 release are needed to explain the increase in mobilised CPCs expressing flk-1 and c-kit. We have previously shown that systemic transplantation of CPCs can induce a potent response from the host's CPCs (Suuronen et al., 2009). Additionally, this effect has been documented in humans, and CPC persistence in the circulation has been observed up to 1 year after cell transplantation (Turan et al., 2010). Therefore, it is likely that the initiation of the SDF-1/ CXCR4 mobilisation and recruitment response by SDF-1 microsphere matrix treatment activates other endogenous progenitor cell mechanisms.

Ischaemia was induced in all mice (average of 55 $\%$ of normal perfusion). By one week post-treatment, animals that received matrix treatment (with or without SDF-1 microspheres) had hindlimb perfusion restored to baseline levels, which is similar to previous reports of matrix treatment for hindlimb ischaemia (Suuronen et al., 2009). It has been previously demonstrated that an increase in perfusion is attributable to increased local vasculature (Kim et al., 2010; Suuronen et al., 2010), an observation that was seen in the current study; matrix treatments increased arteriole density in ischaemic hindlimbs. It was hypothesised that SDF-1 microsphere matrix treatment would confer superior restoration of perfusion, but instead, the matrix-only treatment was equally effective. Kimura and Tabata (2010) also attempted to enhance neovascularisation using an SDF-1-releasing hydrogel, and observed increased capillary density with SDF-1 treatment at $4 \mathrm{~d}$ post-treatment, which was abrogated by 10 d. Another SDF-1 release study did not show a difference in vascular density between SDF-1 and controls at $9 \mathrm{~d}$ posttreatment (Rabbany et al., 2010). It may be that the addition of SDF-1 accelerates the regenerative response to collagen matrix treatment. This is supported by the observation that SDF-1 treatment increased the cross-sectional size of arterioles. Cross-sectional area of new vasculature has been shown to increase over a period of 4 weeks (Ruvinov et al., 2011), demonstrating that vessel area is indicative of vessel maturity. Therefore, it is plausible that SDF-1 treatment had an earlier effect on neovascularisation, allowing for more rapid growth/maturation of arterioles, compared to both matrix and PBS treatments. 
The SDF-1 microsphere matrix treatment recruited the most $\mathrm{GFP}^{+}$marrow-mobilised cells in our animal model. Other SDF-1-release studies have also shown recruitment of stem cells, positive for c-kit (Zhang et al. 2007; Thevenot et al., 2010) expression. In particular, it was expected that SDF-1 treatment would increase the recruitment and engraftment of CXCR4 ${ }^{+}$cells. Both the matrix and SDF-1 microsphere matrix treatments increased homing of bone marrow-derived $\mathrm{CXCR}^{+}$cells to the treated hindlimbs (SDF-1 microsphere matrix treatment had the most pronounced effect), but the SDF-1 microsphere matrix treatment also demonstrated an improved recruitment of $\mathrm{CXCR}^{+}$cells of non-bone marrow origin. Recently, it was shown that local pools of progenitor cells coexpressing CXCR4 and endothelial markers reside in tissues (Sandstedt et al., 2010), suggesting a potential role in neovascularisation. In our experiment, SDF-1 treatment may be recruiting a similar population, as evidenced by CXCR4 ${ }^{+}$GFP $^{-}$staining. Microvascular endothelial cells have also been documented to express CXCR4 (Takagi et al., 2009), suggesting another CXCR4-expressing population that is possibly activated in treated hindlimbs. Regardless, CXCR4 ${ }^{+}$fractions have been observed to be superior to whole CXCR4- fractions with respect to potential for invasion, neovascularisation, and restoration of perfusion (Seeger et al., 2009).

Compared to controls, inflammatory cytokines (IL-1 $\alpha$ and MIP-3 $\alpha$ ) were reduced in hindlimbs treated with SDF-1 microsphere matrix, a result similar to a study by Thevenot et al. (2010). The latter examined cytokine responses to SDF-1 delivery in a synthetic scaffold; however, our results also suggest that the SDF-1 microsphere matrix supports a favourable environment for angiogenic activity through local factors, as evidenced by increased IGF-1 and VCAM1 in hindlimb lysates. IGF-1 is a stimulator of angiogenesis (Su et al., 2003) and is cytoprotective (Li et al., 1997), and elevated IGF-1 is ideal for recovery. Pelosi et al. (2007) have shown that persistent IGF-1 expression accelerates the regenerative response and restores architecture and structure soon after skeletal muscle injury. VCAM-1 is a cell adhesion molecule expressed by endothelial cells. When VCAM-1 is solubilised and detected in serum, it is used as an indicator of dysfunctional endothelium (Balciunas et al., 2009). Our SDF-1 microsphere matrix treatment had significantly less circulating VCAM-1, further suggesting a vasculo-protective role of this therapy. Furthermore, both matrix treatments increased systemic bFGF, which is a potent angiogenic cytokine (Hosseinkhani et al., 2006).

\section{Conclusion}

In this study, we demonstrated that SDF-1 can be successfully encapsulated in an alginate microsphere system and further incorporated into an injectable matrix for non-invasive delivery. The treatment of ischaemic mouse hindlimbs with SDF-1-releasing matrix enhanced progenitor cell mobilisation and recruitment. Compared to collagen-only treatment, the addition of SDF-1 appears to confer an earlier effect on neovascularisation, as suggested by greater arteriole maturity. These findings suggest that application of an SDF-1-releasing matrix constitutes a suitable therapy for prevalent myopathies with reduced perfusion, with the potential to augment progenitor cell mobilisation and homing, as well as its ability to rapidly support neovascularisation.

\section{Acknowledgments}

DK was supported by a Canadian Institutes of Health Research Canadian Graduate Scholarship; PZ is a recipient of the Lawrence Soloway Research Fellowship Award; YZ was supported by a Heart \& Stroke Foundation of Ontario Doctoral Research Award; DTP was supported by a University of Ottawa Cardiology Research Endowment Fellowship; KM was supported by an Ontario Graduate Scholarship; DK and TS were supported by Heart \& Stroke Foundation of Ontario Master's Studentships; JZ was supported by a Natural Sciences and Engineering Research Council of Canada postdoctoral fellowship. The authors would like to thank Suzanne Crowe for her flow cytometry expertise and Ann Fook Yang for assistance with SEM.

This work was supported by grant-in-aid T6793 from the Heart and Stroke Foundation of Ontario (to EJS), by grant MOP-77536 from the Canadian Institutes of Health Research (to MR and EJS), by a Natural Sciences and Engineering Research Council of Canada Research Tool and Instruments Grant (to XC), by a Canadian Stem Cell Network grant (to MG), and by Fondazione Roma and 7FP-Myoage (to AM). Funding sources did not have a role in experimental design, data management, or manuscript preparation.

\section{References}

Askari AT, Unzek S, Popovic ZB, Goldman CK, Forudi F, Kiedrowski M, Rovner A, Ellis SG, Thomas JD, DiCorleto PE, Topol EJ, Penn MS (2003) Effect of stromal-cell-derived factor 1 on stem-cell homing and tissue regeneration in ischaemic cardiomyopathy. Lancet 362: 697-703.

Balciunas M, Bagdonaite L, Samalavicius R, Baublys A (2009) Markers of endothelial dysfunction after cardiac surgery: soluble forms of vascular-1 and intercellular-1 adhesion molecules. Medicina (Kaunas) 45: 434-439.

Belch JJ, Topol EJ, Agnelli G, Bertrand M, Califf RM, Clement DL, Creager MA, Easton JD, Gavin JR $3^{\text {rd }}$, Greenland P, Hankey G, Hanrath P, Hirsch AT, Meyer J, Smith SC, Sullivan F, Weber MA; Prevention of Atherothrombotic Disease Network (2003) Critical issues in peripheral arterial disease detection and management: a call to action. Arch Intern Med 163: 884-892.

Bourne D (2002) Pharmacokinetics. In: Modern Pharmaceuticals, $4^{\text {th }}$ ed. Marcel Dekker Inc., New York, pp 67-92.

Cadee JA, de Groot CJ, Jiskoot W, den Otter W, Hennink WE (2002) Release of recombinant human interleukin-2 from dextran-based hydrogels. J Control Release 78: 1-13.

Cho HJ, Lee N, Lee JY, Choi YJ, Ii M, Wecker A, Jeong JO, Curry C, Qin G, Yoon YS (2007) Role of host tissues for sustained humoral effects after endothelial progenitor 
cell transplantation into the ischaemic heart. J Exp Med 204: 3257-3269.

De Falco E, Porcelli D, Torella AR, Straino S, Iachininoto MG, Orlandi A, Truffa S, Biglioli P, Napolitano M, Capogrossi MC, Pesce M (2004) SDF-1 involvement in endothelial phenotype and ischemia-induced recruitment of bone marrow progenitor cells. Blood 104: 3472-3482.

Deng C, Zhang P, Vulesevic B, Kuraitis D, Li F, Yang AF, Griffith M, Ruel M, Suuronen EJ (2010) A collagenchitosan hydrogel for endothelial differentiation and angiogenesis. Tissue Eng Part A 16: 3099-3109.

Fazel S, Cimini M, Chen L, Li S, Angoulvant D, Fedak P, Verma S, Weisel RD, Keating A, Li RK (2006) Cardioprotective c-kit + cells are from the bone marrow and regulate the myocardial balance of angiogenic cytokines. J Clin Invest 116: 1865-1877.

Formigli L, Perna AM, Meacci E, Cinci L, Margheri M, Nistri S, Tani A, Silvertown J, Orlandini G, Porciani C, Zecchi-Orlandini S, Medin J, Bani D (2007) Paracrine effects of transplanted myoblasts and relaxin on postinfarction heart remodelling. J Cell Mol Med 11: 10871100 .

Hadjiioannou TP, Christian GD, Koupparis MA, Macheras PE (1993) Quantitative Calculations in Pharmaceutical Practice and Research. VCH Publishers Inc., New York, pp 345-348.

Higuchi T (1963) Mechanism of Sustained-Action Medication. Theoretical Analysis of Rate of Release of Solid Drugs Dispersed in Solid Matrices. J Pharm Sci 52: 1145-1149.

Hixson AW, Crowell JH (1931) Dependence of reaction velocity upon surface and agitation (I) theoretical consideration. Ind Eng Chem 23: 923-931.

Hofmann M, Wollert KC, Meyer GP, Menke A, Arseniev L, Hertenstein B, Ganser A, Knapp WH, Drexler $\mathrm{H}$ (2005) Monitoring of bone marrow cell homing into the infarcted human myocardium. Circulation 111: 2198-2202.

Hosseinkhani H, Hosseinkhani M, Khademhosseini A, Kobayashi H, Tabata Y (2006) Enhanced angiogenesis through controlled release of basic fibroblast growth factor from peptide amphiphile for tissue regeneration. Biomaterials 27: 5836-5844.

Kaully T, Kaufman-Francis K, Lesman A, Levenberg S (2009) Vascularisation - the conduit to viable engineered tissues. Tissue Eng Part B Rev 15: 159-169.

Kempen DH, Lu L, Hefferan TE, Creemers LB, Maran A, Classic KL, Dhert WJ, Yaszemski MJ (2008) Retention of in vitro and in vivo BMP-2 bioactivities in sustained delivery vehicles for bone tissue engineering. Biomaterials 29: 3245-3252.

Kim HK, De La Luz Sierra M, Williams CK, Gulino AV, Tosato G (2006) G-CSF down-regulation of CXCR4 expression identified as a mechanism for mobilization of myeloid cells. Blood 108: 812-820.

Kim SW, Kim H, Cho HJ, Lee JU, Levit R, Yoon YS (2010) Human peripheral blood-derived CD31+ cells have robust angiogenic and vasculogenic properties and are effective for treating ischemic vascular disease. J Am Coll Cardiol 56: 593-607.

Kimura Y, Tabata Y (2010) Controlled release of stromal-cell-derived factor-1 from gelatin hydrogels enhances angiogenesis. J Biomater Sci Polym Ed 21: $37-$ 51.

Ko HC, Milthorpe BK, McFarland CD (2007) Engineering thick tissues - the vascularisation problem. Eur Cells Mater 14: 1-18.

Korsmeyer RW, Gurny R, Doelker E, Buri P, Peppas NA (1983) Mechanisms of solute release from porous hydrophilic polymers. Int J Pharm 15: 25-35.

Li Q, Li B, Wang X, Leri A, Jana KP, Liu Y, Kajstura J, Baserga R, Anversa P (1997) Overexpression of insulinlike growth factor- 1 in mice protects from myocyte death after infarction, attenuating ventricular dilation, wall stress, and cardiac hypertrophy. J Clin Invest 100: 1991-1999.

Limbourg A, Korff T, Napp LC, Schaper W, Drexler H, Limbourg FP (2009) Evaluation of postnatal arteriogenesis and angiogenesis in a mouse model of hind-limb ischemia. Nat Protoc 4: 1737-1746.

Liu W, Griffith M, Li F (2008) Alginate microspherecollagen composite hydrogel for ocular drug delivery and implantation. J Mater Sci 19: 3365-3371.

Misiak-Tloczek A, Brzezinska-Blaszczyk E (2009) IL6, but not IL-4, stimulates chemokinesis and TNF stimulates chemotaxis of tissue mast cells: involvement of both mitogen-activated protein kinases and phosphatidylinositol 3-kinase signalling pathways. APMIS 117: 558-567.

Mitra T, Sailakshmi G, Gnanamani A, Raja ST, Thiruselvi T, Gowri VM, Selvaraj NV, Ramesh G, Mandal AB (2011) Preparation and characterization of a thermostable and biodegradable biopolymers using natural cross-linker. Intl J Biol Macromol 48: 276-285.

Murry CE, Reinecke H, Pabon LM (2006) Regeneration gaps: observations on stem cells and cardiac repair. J Am Coll Cardiol 47: 1777-1785.

Park S, Tepper OM, Galiano RD, Capla JM, Baharestani S, Kleinman ME, Pelo CR, Levine JP, Gurtner GC (2004) Selective recruitment of endothelial progenitor cells to ischemic tissues with increased neovascularization. Plast Reconstr Surg 113: 284-293.

Pelosi L, Giacinti C, Nardis C, Borsellino G, Rizzuto E, Nicoletti C, Wannenes F, Battistini L, Rosenthal N, Molinaro M, Musarò A (2007) Local expression of IGF-1 accelerates muscle regeneration by rapidly modulating inflammatory cytokines and chemokines. FASEB J 21: 1393-1402.

Rabbany SY, Pastore J, Yamamoto M, Miller T, Rafii S, Aras R, Penn M (2010) Continuous delivery of stromal cell-derived factor-1 from alginate scaffolds accelerates wound healing. Cell Transplant 19: 399-408.

Ruel M, Suuronen EJ, Song J, Kapila V, Gunning D, Waghray G, Rubens FD, Mesana TG (2005) Effects of offpump versus on-pump coronary artery bypass grafting on function and viability of circulating endothelial progenitor cells. J Thorac Cardiovasc Surg 130: 633-639.

Ruvinov E, Leor J, Cohen S (2010) The effects of controlled HGF delivery from an affinity-binding alginate biomaterial on angiogenesis and blood perfusion in a hindlimb ischemia model. Biomaterials 31: 4573-4582.

Ruvinov E, Leor J, Cohen S (2011) The promotion of myocardial repair by the sequential delivery of IGF-1 and HGF from an injectable alginate biomaterial in a model of acute myocardial infarction. Biomaterials 32: 565-578. 
Sandstedt J, Jonsson M, Lindahl A, Jeppsson A, Asp J (2010) C-kit+ CD45- cells found in the adult human heart represent a population of endothelial progenitor cells. Basic Res Cardiol 105: 545-556.

Seeger FH, Rasper T, Koyanagi M, Fox H, Zeiher AM, Dimmeler S (2009) CXCR4 expression determines functional activity of bone marrow-derived mononuclear cells for therapeutic neovascularization in acute ischemia. Arterioscl Thromb Vasc Biol 29: 1802-1809.

Selvin E, Erlinger TP (2004) Prevalence of and risk factors for peripheral arterial disease in the United States: results from the National Health and Nutrition Examination Survey, 1999-2000. Circulation 110: 738-743.

Shamoun F, Sural N, Abela G (2008) Peripheral artery disease: therapeutic advances. Expert Rev Cardiovasc Ther 6: 539-553.

Su EJ, Cioffi CL, Stefansson S, Mittereder N, Garay M, Hreniuk D, Liau G (2003) Gene therapy vectormediated expression of insulin-like growth factors protects cardiomyocytes from apoptosis and enhances neovascularization. Am J Physiol Heart Circ Physiol 284: H1429-1440.

Suuronen EJ, Price J, Veinot JP, Ascah K, Kapila V, Guo XW, Wong S, Mesana TG, Ruel M (2007) Comparative effects of mesenchymal progenitor cells, endothelial progenitor cells, or their combination on myocardial infarct regeneration and cardiac function. J Thorac Cardiovasc Surg 134: 1249-1258.

Suuronen EJ, Zhang P, Kuraitis D, Cao X, Melhuish A, McKee D, Li F, Mesana TG, Veinot JP, Ruel M (2009) An acellular matrix-bound ligand enhances the mobilization, recruitment and therapeutic effects of circulating progenitor cells in a hindlimb ischemia model. FASEB J 23: 1447-1458.

Suuronen EJ, Hazra S, Zhang P, Vincent R, Kumarathasan P, Zhang Y, Price J, Chan V, Sellke FW, Mesana TG, Veinot JP, Ruel M (2010) Impairment of human cell-based vasculogenesis in rats by hypercholesterolemia-induced endothelial dysfunction and rescue with L-arginine supplementation. J Thorac Cardiovasc Surg 139: 209-216. e2.

Takagi Y, Hashimoto N, Phan SH, Imaizumi K, Matsuo M, Nakashima H, Hashimoto I, Hayashi Y, Kawabe T, Shimokata K, Hasegawa Y (2009) Erythromycin-induced CXCR4 expression on microvascular endothelial cells. Am J Physiol 297: L420-431.

Thevenot PT, Nair AM, Shen J, Lotfi P, Ko CY, Tang L (2010) The effect of incorporation of SDF-1alpha into PLGA scaffolds on stem cell recruitment and the inflammatory response. Biomaterials 31: 3997-4008.

Turan RG, Bozdag-Turan I, Ortak J, Akin I, Kische S, Schneider H, Turan CH, Rehders TC, Rauchhaus M, Kleinfeldt T, Adolph E, Brehm M, Yokus S, Steiner $\mathrm{S}$, Sahin K, Nienaber CA, Ince H (2010) Improved mobilization of the CD34(+) and CD133(+) bone marrowderived circulating progenitor cells by freshly isolated intracoronary bone marrow cell transplantation in patients with ischemic heart disease. Stem Cells Dev, in press.

Whitman SC, Rateri DL, Szilvassy SJ, Yokoyama W, Daugherty A (2004) Depletion of natural killer cell function decreases atherosclerosis in low-density lipoprotein receptor null mice. Arterioscl Thromb Vasc Biol 24: 10491054.

Wojakowski W, Tendera M, Michalowska A, Majka M, Kucia M, Maslankiewicz K, Wyderka R, Ochała A, Ratajczak MZ (2004) Mobilization of CD34/CXCR4+, CD34/CD117+, c-met+ stem cells, and mononuclear cells expressing early cardiac, muscle, and endothelial markers into peripheral blood in patients with acute myocardial infarction. Circulation 110: 3213-3220.

Yang J, Wang F, Tianwei T (2010) Degradation behavior of hydrogel based on crosslinked poly(aspartic acid). J Appl Polym Sci 117: 178-185.

Zhang G, Nakamura Y, Wang X, Hu Q, Suggs LJ, Zhang J (2007) Controlled release of stromal cell-derived factor-1 alpha in situ increases c-kit+ cell homing to the infarcted heart. Tissue Eng 13: 2063-2071.

\section{Discussion with Reviewers}

Reviewer II: Could the authors foresee applications for their injectable hydrogel loaded with SDF1 microspheres in damaged bone tissue with compromised vascularity?

Authors: Vascularisation is believed to play an important role in bone wound healing (Giannoudis et al., 2008, additional reference), yet defective neovascularisation in some patients leads to an avascular fracture site. A recent study reported that inhibiting angiogenesis in a rat tibia osteotomy model resulted in non-union of the fracture over the early healing stages, demonstrating the importance of the vasculature for proper bone wound repair (Fassbender et al., 2011, additional reference). Notably, the local application of SDF-1 was able to increase neo-blood vessel maturation leading to accelerated bone regeneration, characterised by increased callus formation in a distraction osteogenesis model (Fujio et al., 2011, additional reference). Therefore, we can envision that a strategy such as the system reported here may be applicable in bone trauma, whereby blood vessel growth is stimulated at the early stages after bone injury, possibly allowing for more effective wound healing to occur, and without delay.

Reviewer II: In the discussion, the authors suggest that the matrix is important to support the reperfusion and that SDF-1 supports early neovascularisation. Would it be possible that a burst release of SDF-1 from a hydrogel matrix would be equivalent or even better than the material solution proposed with a relatively long release profile?

Authors: After the induction of limb ischaemia, the natural in vivo response is that of a burst-release of SDF1 (De Falco et al., 2004, text reference). This is also suggested by the observation that patients with acute limb ischaemia have greater levels of SDF-1 than those with chronic ischaemia (van Weel et al., 2007, additional reference). However, the data so far suggests that a prolonged release and presence of SDF-1 is superior to burst release in improving angiogenesis. For example, this has been demonstrated for subcutaneous implantation (Kimura and Tabata, 2010, text reference) and for the repair of ischaemic cardiac tissue (Segers et al., 2007, additional reference; Sundararaman et al., 2011, additional 
reference). However, in the present study, we observed an increase in vessel size, but no difference in vascular density between the two matrix treatments (+/- SDF-1 release), suggesting that the SDF-1 effect was early and accelerated the regeneration response conferred by the injected collagen matrix. Therefore, it is conceivable that a burst release of SDF-1 from microspheres to augment the body's natural SDF-1 release response may be as good as, or better than, prolonged release for treatment strategies involving therapeutic matrix injections. However, we also cannot exclude the possibility that the prolonged presence of SDF-1 may have a role in other effects, such as the vessel maturation process, or the prevention of apoptosis, which have been reported previously by others (Reddy et al., 2008, additional reference; Ho et al., 2010, additional reference), but were not examined in the present study.

\section{Additional References}

Fassbender M, Strobel C, Rauhe JS, Bergmann C, Schmidmaier G, Wildemann B (2011) Local inhibition of angiogenesis results in an atrophic non-union in a rat osteotomy model. Eur Cells Mater 22: 1-11.

Fujio M, Yamamoto A, Ando Y, Shohara R, Kinoshita K, Kaneko T, Hibi H, Ueda M (2011) Stromal cell-derived factor-1 enhances distraction osteogenesis-mediated skeletal tissue regeneration through the recruitment of endothelial precursors. Bone, in press.
Giannoudis PV, Einhorn TA, Schmidmaier G, Marsh D (2008) The diamond concept - open questions. Injury 39: 5-8.

Ho TK, Tsui J, Xu S, Leoni P, Abraham DJ, Baker DM (2010) Angiogenic effects of stromal cell-derived factor-1 (SDF-1/CXCL12) variants in vitro and the in vivo expressions of CXCL12 variants and CXCR4 in human critical leg ischemia. J Vasc Surg 51: 689-699.

Reddy K, Zhou Z, Jia SF, Lee TH, Morales-Arias J, Cao Y, Kleinerman ES (2008) Stromal cell-derived factor-1 stimulates vasculogenesis and enhances Ewing's sarcoma tumor growth in the absence of vascular endothelial growth factor. Int J Cancer 15: 831-837.

Segers VF, Tokunou T, Higgins LJ, MacGillivray C, Gannon J, Lee RT (2007) Local delivery of proteaseresistant stromal cell derived factor-1 for stem cell recruitment after myocardial infarction. Circulation 116: 1683-1692.

Sundararaman S, Miller TJ, Pastore JM, Kiedrowski M, Aras R, Penn MS (2011) Plasmid-based transient human stromal cell-derived factor-1 gene transfer improves cardiac function in chronic heart failure. Gene Ther, in press.

Van Weel V, Toes RE, Seghers L, Deckers MM, de Vries MR, Eilers PH, Sipkens J, Schepers A, Eefting D, van Hinsbergh VW, van Bockel JH, Quax PH (2007) Natural killer cells and CD4+ T-cells modulate collateral artery development. Arterioscler Thromb Vasc Biol 27: 2050-2057. 